\title{
PATTERN OF PREVENTION-OF-MOTHER-TO-CHILD-TRANSMISSION SERVICE BY PRIVATE HOSPITALS IN MAKURDI, NIGERIA
}

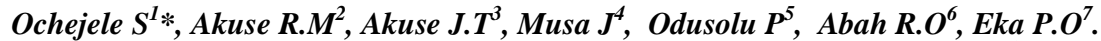 \\ Departments of Obstetrics and Gynaecology, Federal Medical Centre Makurdi ${ }^{1}$, Sefa Specialist Hospital Kaduna ${ }^{3}$, Jos University \\ Teaching Hospital ${ }^{4}$, University of Calabar Teaching Hospital ${ }^{5}$ \& Benue State University Teaching Hospital Makurdi ${ }^{7}$. \\ Departments of Paediatrics, Ahmadu Bello University Teaching Hospital, Zaria ${ }^{2}$ and Benue State University Teaching Hospital Makurdi. ${ }^{6}$
}

*Correspondence Author: Dr Silas Ochejele, Department of Obstetrics and Gynaecology, Federal Medical Centre Makurdi. E-mail: silasfriday@yahoo.com.

Received date: March $05^{\text {th }}, 2018$, Accepted date: March $26^{\text {th }}$ 2018. Published date: June $30^{\text {th }} 2018$.

\section{Abstract}

Nigeria has the highest number of new HIV infections worldwide and Benue State was reported to have the highest HIV Prevalence in the country. These may partly be due to low coverage of Prevention-of-Mother-to-child-transmission services in private hospitals. Prevention-of-Mother-to-Child-Transmission outlets are concentrated in public facilities but many people patronize private hospitals. This study assessed Prevention-of-Mother-to-Child-Transmission Service provision by private hospitals in Makurdi. A Cross sectional survey of 12 (private-for-profit) registered hospitals with facilities for antenatal and delivery care was carried out. Information was obtained using structured questionnaires. All hospitals performed HIV testing. Six (50\%) routinely counseled all pregnant women for testing. Eight (66.7\%) offered Prevention-ofMother-to-Child-Transmission Services. Four (33.3\%) had staff trained in Prevention-of-Mother-to-Child-Transmission but one hospital where only midwives were trained did not provide Prevention-of-Mother-to-Child-Transmission Services. Five $(41.7 \%)$ of the hospitals gave antiretroviral prophylaxis, none had facilities for CD4 count or viral load. A total of 4(50\%) of the facilities provided care for infants but only one collected samples for early infant diagnosis. Service delivery appeared to be influenced by cost and staff training. Gaps in service delivery included lack of routine HIV testing, inadequate ARV prophylaxis, inadequate care and support to infants and family members, limited laboratory capacity and use of obstetric procedures which could increase transmission. Private health facilities need support from governments and international partners. Care must be taken to involve medical directors of hospitals in training, provide regular updates about protocols and linkages with other organizations offering services they lack. This would increase service coverage, improve quality of services and source data on Prevention-of-Mother-to-Child-Transmission Services.

Keywords: Nigeria, Prevention-of-Mother-to-Child-Transmission, PMTCT, Health Care, Private.

\section{Introduction}

In 2011, a Global Plan was launched to reduce the number of new HIV infections via mother-to-child transmission by $90 \%$ by $2015 .{ }^{1}$ In 2015 , six priority countries (Botswana, Mozambique, Namibia, South Africa, Swaziland and Uganda) met the Global Plan target of reducing mother-to-child transmission by $90 \% .^{2}$ However in Nigeria, the most populous country in Africa only $36 \%$ of HIV infected pregnant women received antiretroviral (ARV) drugs and new child HIV infections declined by just $21 \%{ }^{3}$ with an estimated 41,000 children becoming infected with HIV. ${ }^{4}$ Nigeria, with a population of $162,265,000^{5}$, has one of the highest HIV and AIDS epidemic burdens worldwide. ${ }^{6}$ It has a generalized epidemic with a prevalence of $4.1 \%^{7}$, an estimated 3.1 million persons living with HIV, 2,215,130 AIDS related deaths annually and 2,229,883 total AIDS orphans. ${ }^{8}$ In 2001, the country adopted the United Nations General Assembly Special Session goal of reducing the proportion of infants infected with HIV by $20 \%$ by 2005 and $50 \%$ by 2010 . However, with approximately 60,000 new paediatric HIV infections in 2012, it was obvious that these goals were not achieved and Nigeria accounts for $30 \%$ of the global PMTCT gaps. ${ }^{9}$ Though the country has made some progress in the expansion of Prevention of Mother-to-childtransmission (PMTCT) services, critical bottlenecks still exist that impede availability and access to these services. Following the launch of the Global Plan towards the elimination of new HIV infections among 
children (eMTCT). ${ }^{10}$ and the alignment of the National eMTCT Scale-up Plan to the global elimination targets, the Nigerian response has increased its focus on its PMTCT programme. In order to achieve the United Nations Global Plan target of eliminating new HIV infections in children. ${ }^{11,12}$ The National Agency for the Control of AIDS (NACA) has advocated for decentralization of PMTCT services to include private and rural health facilities. This is because despite the rapid expansion of public sector highly active antiretroviral (ARV) treatment programs, the private sector also continues to treat patients for HIV/AIDS. In December 2005, the WHO estimated that about $21 \%$ of those receiving ARV therapy (ART) in six high-prevalence African countries (South Africa, Namibia, Botswana, Nigeria, Kenya, and Uganda) were being treated in the private sector. ${ }^{13}$ Benue State (one of the 36 states in Nigeria), has one of the highest HIV prevalence rates ${ }^{14}$ among pregnant women attending antenatal clinics (ANC) in Nigeria.

Prevalence rates rose from $10 \%$ in $2005,10.6 \%$ in 2008 , and $12.7 \%$ in $2010^{15}$. Non-involvement of many private hospitals and rural health facilities in the provision of PMTCT services has been identified as a major challenge to PMTCT intervention in the state ${ }^{16}$. If new HIV infections among children are to be eliminated and the set targets attained in Nigeria, greater effort needs to be made to increase PMTCT coverage. The private sector offers various HIV/AIDS services but is often overlooked in HIV/AIDS programs and governments and international donors have concerns about the quality of care they provide. Information on PMTCT service provision is useful in planning strategies to increase PMTCT coverage. The aim of this study was to assess PMTCT service provision by formal private health practitioners in Makurdi the capital of Benue state specifically, to determine which PMTCT services they provide and identify gaps in service delivery. It is hoped that the findings would assist policy makers develop strategies that could improve PMTCT services and increase coverage not just in Nigeria but wherever private providers offer PMTCT services.

\section{Materials and Methods}

The study was carried out in 2010 in Makurdi the capital of Benue state as part of a project funded by World Bank Assisted HIV/AIDS Fund (HAF 3). Makurdi has a comprehensive centre for HIV/AIDS situated in a government health facility. The centre provides free PMTCT services for adults and children as well as specialised laboratory services. Yet as in other parts of the country, a proportion of the population in Makurdi utilize private health providers. Twelve hospitals situated in different parts of Makurdi were randomly selected from a list of 500 health facilities supplied by the Benue State Ministry of Health. Only private-for-profit secondary level hospitals which were registered with the State government, and which had facilities for antenatal care and delivery were studied. The tool used for assessment was a structured questionnaire which was given to the Medical Director of each hospital to fill. He was allowed to consult staff of his hospital. The questionnaire was adapted from that used by UNICEF for mapping and assessment of PMTCT sites in Nigeria and the Family Health International (FHI) Institute for HIV/AIDS PMTCT Assessment. It included questions about standard PMTCT interventions including HIV counseling and testing of pregnant women; administration of ARV prophylaxis; counseling about nutrition and safe infant feeding options; use of safe obstetric practices; diagnosis and treatment of opportunistic infections; infant care including facilities for early infant diagnosis; family planning services, services available for care and support of family members. There were also questions about Human resource availability, training of health workers, laboratory services and cost of services.

Hospitals offering PMTCT services were classified into two categories.

Group A - Those reporting that at a minimum, they offer HIV testing and counseling on nutrition and/or infant feeding, but do not provide ARV prophylaxis for HIV positive women.

Group B- Those reporting that at a minimum, they offer testing and ARV prophylaxis for HIV positive women.

\section{Data analysis}

Data from the questionnaire was analyzed using SPSS version 16 (SPSS Inc., Chicago, IL, USA).

\section{Results}

\section{PMTCT services offered}

Eight $(66.7 \%)$ offered various PMTCT services. Three $(37.5 \%)$ of these 8 , were classified as group A while $5(62.5 \%)$ were classified as Group B. Three (37.5\%) hospitals (all of which were group B hospitals) had 
various staff trained in PMTCT. These were doctors, midwives, nurses, and laboratory staff). In contrast none of the group A hospitals had staff trained in PMTCT. All hospitals offered HIV testing (most rapid testing) but none had facilities for western blot, CD4 count determination, viral load or Polymerase Chain Reaction (PCR).
Table 1: Fees-for-service charged by the hospitals

\begin{tabular}{ll}
\hline Service & Charge \\
\hline HIV testing & $\mathrm{N} 300-\mathrm{N} 3,000$ \\
ANC Booking & $\mathrm{N} 400-\mathrm{N} 4,000$ \\
ANC Revisit & $\mathrm{N} 100-\mathrm{N} 3,500$ \\
Normal delivery fees & $\mathrm{N} 2,500-\mathrm{N} 10,000$ \\
Caesarean section fees & $\mathrm{N} 25,000-\mathrm{N} 50,000$ \\
\hline
\end{tabular}

Table 2: Prevention of Mother-To-Child-Transmission (PMTCT) service provision

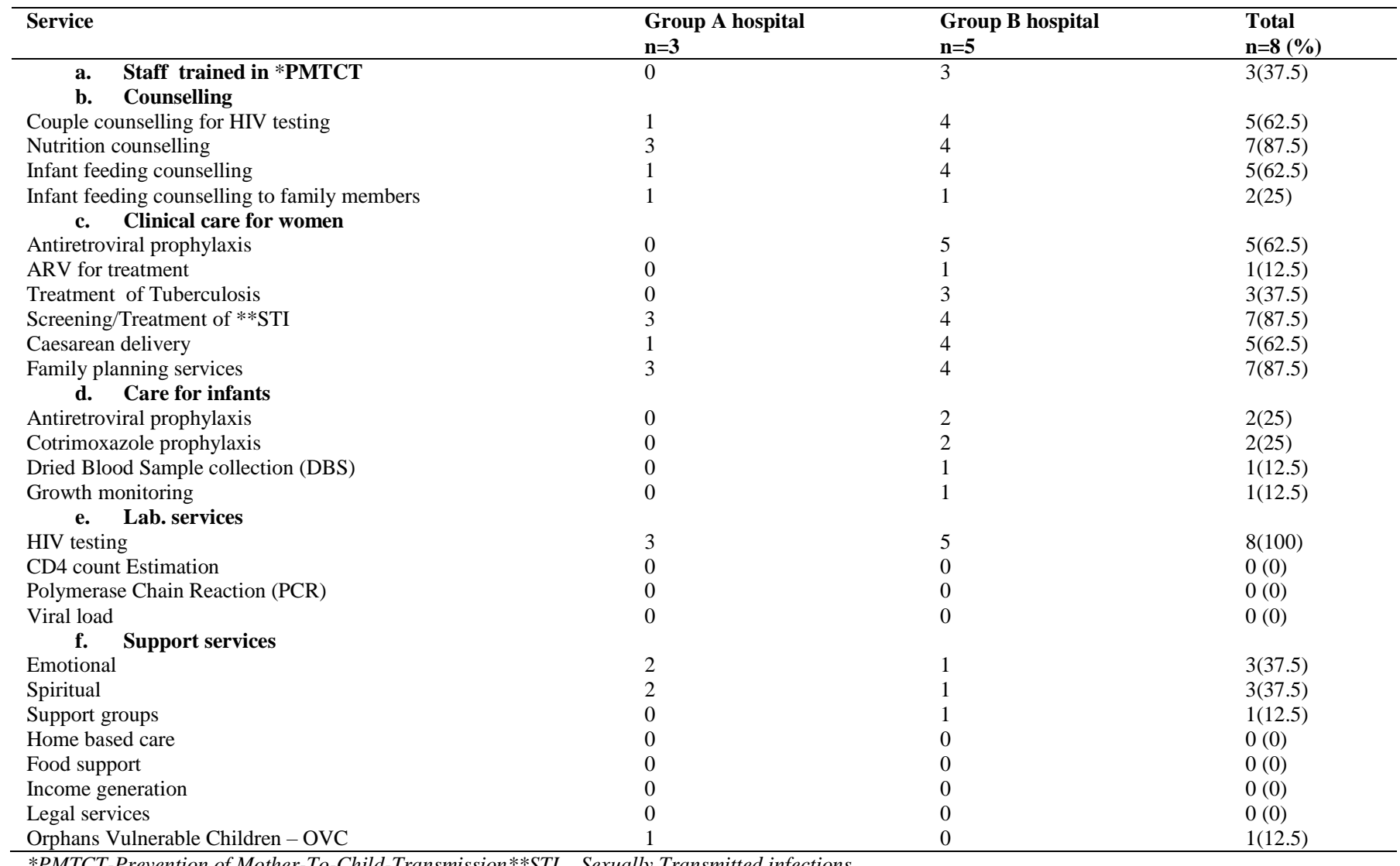

\section{Care of HIV exposed infants}

The result shows a total of $4(50 \%)$ facilities, all in group B providing clinical care to HIV exposed infants. provided clinical care to HIV exposed infants. Care consisted of ARV prophylaxis, cotrimoxazole syrup and vitamin preparations. Only one hospital collected Dried Blood Samples (DBS) for early infant diagnosis (EID). Advice about infant feeding consisted mainly of use of infant formula but information was also given about other options (exclusive breast feeding with early cessation, heated expressed breast milk, wet nursing or animal milk).

\section{Family planning}

Most hospitals $7(87.5 \%)$ providing PMTCT services also provided family planning services (commonly condoms, and intrauterine contraceptive devices (IUCDs). The cost of IUCDs was not covered by the NHIS.

\section{Support services}

A few hospitals offered emotional and spiritual support but none had home based care, food support, or advice about income generation or legal services. 


\section{Discussion}

Most $8(67 \%)$ of the private-for-profit hospitals offered various core PMTCT interventions. However despite their potential capacities, it appeared that the comprehensiveness of their services was constrained by cost and training of staff. Gaps in service delivery included lack of routine HIV testing of all pregnant women, inadequate or no ARV prophylaxis, inadequate care and support of infants and other family members, limited laboratory capacity and obstetric procedures which could increase MTCT.

Despite the effectiveness of the highly active antiretroviral therapy in suppressing viral replication, restoring immune functions, ${ }^{17,18}$ extending survival and reducing HIV/AIDS-related morbidity in African populations..$^{19,20,21}$ Only $1(12.5 \%)$ of the surveyed facilities provided adequate ART for PMTCT. The landmark initiation of the antiretroviral therapy programme by the Federal government of Nigeria in 2002 did not only increase access and uptake of treatment for eligible Nigerians living with HIV but transformed HIV from a fatal disease to a chronic disease in the country. ${ }^{22,23}$ Increasing the number of individuals receiving antiretroviral therapy (ART) is the current priority of the Nigerian Government. ${ }^{24}$ All the surveyed facilities had maternal and child health services which could be used for PMTCT integration. Thus women not accessing care in the public sector could benefit from PMTCT services if offered in private hospitals. Having private health care providers on board would alleviate patient load on public facilities, provide services at shorter waiting times, reduce patient's stigmatization, and provide more flexible appointment scheduling. ${ }^{25,26,27,28,29}$ Until the dramatic fall in prices of antiretroviral (ARV) drugs after the Thirteenth International AIDS Conference in 2000 and the advent of major donor funding for public ARV treatment programs, such as the President's Emergency Plan for AIDS Relief (PEPFAR) and the Global Fund to Fight AIDS, Tuberculosis, and Malaria (Global Fund), the private sector was the only source of highly active ARV treatment (HAART) in most African countries ${ }^{30}$ The introduction of ART services in Nigeria has significantly impacted positively on the overall wellbeing of People living with HIV/AIDS (PLHIVs). ${ }^{31}$ In 2004, expanding access to treatment through free antiretroviral therapy (ART) was adopted as one of the measures which could extend and improve the quality of lives of people living with HIV especially in low- and middleincome countries. ${ }^{32}$

However training of health workers appeared to affect provision of ARV e.g. group A hospitals which did not have staff trained in PMTCT service provision did not administer ARVs.

Another major service gap was that many hospitals did not provide care for HIV exposed infants. Care includes early infant diagnosis (EID) which identifies infected infants and increases their survival. As only one hospital collected Dried Blood Samples (DBS), the possibility of infected infants being diagnosed early was limited. It was outside the scope of the study to determine what happened to these children but PMTCT programs often report that many HIV exposed infants are lost to follow up. ${ }^{33,34}$ There is need to determine if such loss could be minimized through assisting private hospitals to provide EID and improve infant care in the first few months. DNAPCR used for EID is only available in specialized laboratories but hospitals could be encouraged to collect dried blood samples (DBS) which would then be sent to a regional laboratory.

The study provides information about PMTCT service provision by private health establishments but was limited to those registered by the state government. Their responses may or may not be representative of other health providers who were not registered and thus not regulated by the authorities. Further the study did not determine if there was a difference between reported and actual practices.

It is recommended that PMTCT programs be expanded to include formal private health providers so as to increase coverage of PMTCT. However it should be realized that the facilities charged for services because they had to buy commodities. If governments and international partners could subsidize costs of services, provide training, ARVs, access to specialized laboratories and care and support programs, this would improve the quality of services the facilities provide. Regular updates of guidelines are also needed as well as linkages to organizations that offer support services which most of the private health providers were unable to provide. Research involving a larger number of providers is needed to determine other factors that may be associated with service provision. 


\section{Conclusion}

Private health facilities should be supported by the government and international partners to implement PMTCT interventions. This will facilitate the attainment of the Federal Government's goal of increasing the coverage of PMTCT/ART/HIV services in the country.

\section{References}

1. Aids portal (2015,25 June). Wide political support for eliminating 90 per cent of new HIV infections in children is yielding impressive results

2. UNAIDS (2016). On the Fast track to an AIDS-free generation [pdf]

3. UNAIDS (2016). Get on the Fast track : The Life Cycle Approach to HIV[pdf]

4. UNAIDS (2016). Prevention Gap Report[pdf]

5. National Agency for the Control of AIDS. (2012). Global AIDS Response Country Progress Report: Nigeria GAPR 2012

6. WHO/UNAIDS/UNICEF 2011

7. Federal Ministry of Health (2010). National HIV Sero Prevalence Sentinel Survey. FMOH Abuja Nigeria

8. National Agency for the Control of AIDS. (2011). Factsheet 2011: Update on the HIV/AIDS Epidemic and Response in Nigeria. NACA, Abuja, Nigeria.

9. UNAIDS. UBRAF 2012-2015 Country Case Study: Nigeria. Geneva: UNAIDS; 2011

10. UNAIDS 2013 progress report on the Global Plan towards the elimination of new HIV infections among children by 2015 and keeping their mothers alive. 2013. [Accessed December 15, 2013]. Availablefrom:http://www.zero-hiv.org/wpcontent/uploads/2013/06/2013-progress-on-the-global-plan-en.pdf.

11. Gourlay A, Birdthistle I, Mburu G, Iorpenda K, Wringe A. Barriers and facilitating factors to the uptake of antiretroviral drugs for prevention of mother-to-child transmission of HIV in sub-Saharan Africa: a systematic review. J Int AIDS Soc. 2013;16:18588.

12. Joint United Nations Programme on HIV/AIDS. Global Plan towards the elimination of new HIV infections among children by 2015 and keeping their mothers alive: 2011-2015. Geneva, Switzerland: United Nations; 2011.

13. World Health Organization Progress in Global Access of HIV Antiretroviral

Therapy. http://www.who.int/hiv/fullreport_en_highres.pdf. Accessed June 9, 2007.

14. Hilhorst T, Liere MK, Konig K. Impact of AIDS on rural livelihood in Benue State, Nigera. Sahara J (Journal of Social Aspect of HIV/AIDS Research Alliance). 2001; 3: 3-6

15. Federal Ministry of Health, Abuja, Nigeria. ANC HIV Sentinel Survey, Federal Ministry of Health. Abuja, Nigeria: 2010. [Accessed October 10, 2013]. Available from:http://data.unaids.org/pub/Report/2010/nigeria_2010_country_p rogress_report_en.pdf.

16. Anígilájé EA, Ageda BR, Nweke NO (2016). Barriers to uptake of prevention of mother-to-child transmission of HIV services among mothers of vertically infected HIV-seropositive infants in Makurdi, Nigeria. https//doi.org/10.2147/PPA.S87228 Volume 2016:10 Pages 57-72.

17. Sterne JA, Hernan MA, Ledergerber B, Tilling K, Weber R, Sendi P et al. Long-term effectiveness of potent antiretroviral therapy in preventing AIDS and death: a prospective cohort study. Lancet 2005;366(9483):378-84.

18. Marins JR, Jamal LF, Chen SY, Barros MB, Hudes ES, Barbosa AA et al. Dramatic improvement in survival among adult Brazilian AIDS patients. AIDS 2003;17(11):1675-82.
19. Bekker LG, Myer L, Orrell C, Lawn S, Wood R. Rapid scale-up of a community-based HIV treatment service: programme performance over 3 consecutive years in Guguletu, South Africa. S.Afr.Med J. 2006;96(4):315-22.

20. Laurent C, NgomGueye NF, Ndour CT, Gueye PM, Diouf M, Diakhate $\mathrm{N}$ et al. Long term benefits of highly active antiretroviral therapy in Senegalese HIV-1-infected adults. J.Acquir.Immune.Defic.Syndr. 2005;38(1):14-7.

21. Wester CW, Kim S, Bussmann H, Avalos A, Ndwapi N, Peter TF et al. Initial response to highly active antiretroviral therapy in HIV-1Cinfected adults in a public sector treatment program in Botswana J.Acquir.Immune.Defic.Syndr. 2005;40(3):336-43.

22. Ezechi OC, Peterson KO, Okolo CA, Ujah IAO, Ostergren PO. The Association between HIV Infection, antiretroviral therapy and cervical squamous intraepithelial lesions in South Western Nigerian women. PLoS ONE 2014; 9: e97150. doi:10.1371/journal.pone.0097150

23. Idigbe EO, Adewole TA, Eisen G Kanki P, Odunukwe NN, Onwujekwe DI et al. Management of HIV-1 infection with a combination of nevirapine, stavudine, and lamivudine: a preliminary report on the Nigerian antiretroviral program. JAIDS 2005; 40: 6569.

24. National Agency for the Control of AIDS. National HIV/AIDS strategic plan 2010-2015. 2010.

25. Ezechi OC1, Oladele DA, Dureke F, Anenih J, Ogungbemi K, Folayan MO. Private Sector Engagement in the National HIV Response in Nigeria: Findings from a Nationally Representative Sample of Stakeholders. Nigerian Journal of Health Sciences 2014 14: 00

26. Feeley F, Connelly P, Rosen S. Private sector provision and financing of AIDS treatment in Africa: current developments. Current HIV/AIDS Reports 2007; 4: 192- 200.

27. Ilavenil R, Reich MR. Public-private partnerships and antiretroviral drugs for HIV/AIDS: lessons from Botswana. Health Affairs 2005; 24: 545-551.

28. Ilavenil R, Reich MR. Building effective public-private partnerships: Experiences and lessons from the African Comprehensive HIV/AIDS Partnerships (ACHAP). Social Science \& Medicine 2006; 63: 397 408.

29. Idoko J. A clinician's experience with the President's Emergency Plan for AIDS Relief in Nigeria: a transformative decade of hope Health Affairs 2012; 31: 1422-1428.

30. Feeley F, Connelly P, Rosen S. Private Sector Provision and Financing of AIDS Treatment in Africa: Current Developments. Current HIV/AIDS Reports 2007, 4:192-200.

31. Nwabueze SA, Adogu POU, Ilika AL, Asuzu MC. 2010 Comparative Analysis of Patients Satisfaction Levels in HIV/AIDS Care in Secondary and Tertiary Health Care Facilities in Nigeria. Afrimedic Journal, 2: 1-9.

32. Osungbade KO, Shaahu VN, Owoaje EE, Adedokun BO.2013.

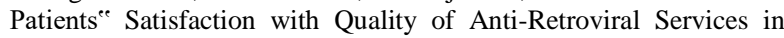
Central Nigeria: Implications for Strengthening Private Health Services. World Journal of Preventive Medicine. 2013;1(3):11-18. Retrieved May 18th, 2015 from http://pubs.sciepub.com/jpm/1/3/1

33. Rawizza HE, Chang CA, Chaplin B, Ahmed IA, Meloni ST, Oyebode T, Banigbe B, Sagay AS, Adewole IF, Okonkwo P, Kanki PJ; APIN PEPFAR Team. Loss to Follow-Up within the Prevention of Mother-to-Child Transmission Care Cascade in a Large ART Program in Nigeria.Curr HIV Res. 2015; 13(3):201-9.

34. Kyaw KWY, OO MM, Kyaw NTT, Phyo KH, Aung TK, Mya T, Aung N, OO HN, IsaakidisP.Low mother-to-child HIV transmission rate but high loss-to-follow-up among mothers and babies in Mandalay, Myanmar; a cohort study.PLoS One. 2017 8;12(9):e0184426.doi:10.1371/journal.pone.0184426. eCollection 2017. 